Ramon M. Coral-Vazquez • Haydee Rosas-Vargas

Pedro Meza-Espinosa • Irma Mendoza

Juan C. Huicochea • Guillermo Ramon • Fabio Salamanca

\title{
Severe congenital muscular dystrophy in a Mexican family with a new nonsense mutation (R2578X) in the laminin $\alpha-2$ gene
}

\begin{abstract}
The congenital muscular dystrophies (CMDs) are a heterogeneous group of autosomal recessive disorders. Approximately one half of cases diagnosed with classic CMD show primary deficiency of the laminin $\alpha 2$ chain of merosin. Complete absence of this protein is usually associated with a severe phenotype characterized by drastic muscle weakness and characteristic changes in white matter in cerebral magnetic resonance imaging (MRI). Here we report an 8-month-old Mexican female infant, from a consanguineous family, with classical CMD. Serum creatine kinase was elevated, muscle biopsy showed dystrophic changes, and there were abnormalities in brain MRI. Immunofluorescence analysis demonstrated the complete absence of laminin $\alpha 2$. In contrast, expression of $\alpha-, \beta-, \gamma-$, and $\delta$-sarcoglycans and dystrophin, all components of the dystrophin-glycoprotein complex, appeared normal. A homozygous $\mathrm{C} \rightarrow \mathrm{T}$ substitution at position 7781 that generated a stop codon in the $\mathrm{G}$ domain of the protein was identified by mutation analysis of the laminin $\alpha 2$ gene (LAMA2). Sequence analysis on available DNA samples of the family showed that parents and other relatives were carriers of the mutation.
\end{abstract}

Key words Congenital muscular dystrophy - Laminin $\alpha 2$. Merosin $\cdot L A M A 2 \cdot$ Immunofluorescence $\cdot$ Mutation

R.M. Coral-Vazquez $(\bowtie) \cdot$ H. Rosas-Vargas $\cdot$ P. Meza-Espinosa

I. Mendoza $\cdot$ J.C. Huicochea $\cdot$ F. Salamanca

Unit of Medical Research in Human Genetics, Children's Hospital,

XXI Century National Medical Center-IMSS, AV Cuauhtemoc No.

330, Col. Doctores, Delegacion Cuauhtemoc, Mexico City 06725,

Mexico

Tel. +52-55-627-6941; Fax +52-55-761-0952

e-mail: rmcoral@correo.unam.mx

G. Ramon

Pathology Department, Children's Hospital, XXI Century National Medical Center-IMSS, Mexico City, Mexico

The first two authors contributed equally to this work.

\section{Introduction}

Congenital muscular dystrophies (CMDs) are a heterogeneous group of neuromuscular disorders characterized by muscular dystrophy and are further divided according to different degrees of central nervous system involvement (Banker 1994). In this group is included classic or pure CMD (OMIM 156225), Fukuyama CMD (OMIM 253800), $\alpha 7$ integrin congenital myopathy (OMIM 600536), rigid spin CMD (OMIM 602771), and muscle-eye-brain disease (OMIM 253280). The classic form of CMD without mental deficiency presents muscle weakness with hypotonia and weakness at birth or within the first few months of life (Tome et al. 1994). Levels of serum creatine kinase (CK) are normal or moderately raised. Although intelligence remains normal, magnetic resonance imaging (MRI) of the brain shows white matter changes (Tome et al. 1994; Dubowitz 1994). Deficient expression of the laminin $\alpha 2$ chain has been identified in approximately $50 \%$ of cases with classical CMD (Sewry et al. 1995). Laminin $\alpha 2$ CMD, also known as merosin-deficient CMD (MDC1A), shows autosomal recessive inheritance (Tome et al. 1994); the locus of the gene (LAMA2) was located by linkage analysis on 6q2 (Hillarie et al. 1994; Naom et al. 1997) and is composed of 64 exons (Zhang et al. 1996). Participation of $L A M A 2$ in CMD was also determined by identification of mutations in the gene in some patients (Helbling-Leclerc et al. 1995; Pegoraro et al. 1996; Guicheney et al. 1998).

It has been observed that the severe phenotype is caused by mutations that drastically affect the expression of LAMA2 or the structure of the protein (Nissinen et al. 1996; Pegoraro et al. 1996; Guichenney et al. 1998; Pegoraro et al. 1998). On the other hand, a wide range of milder phenotypes in CMD patients are caused by partial merosin deficiency, which can be produced by an in-frame deletion in LAMA2 (Allamand et al. 1997), or mutations that permit production of a partially functional protein or a reduced amount of normal protein (Naom et al. 1998, 2000). 
Fig. 1. A Pedigree of the consanguineous family affected with congenital muscular dystrophy. Arrow and filled ellipse indicate index case; ellipses and boxes with center dot represent carriers of mutation. B Automated partial nucleotide sequence of $L A M A 2$ exon 54. The patient (right panel) has a $\mathrm{C} \rightarrow \mathrm{T}$ substitution at position 7781 , which changes arginine to a stop codon (R2578X). The parents (IV-1, IV-2) and other relatives (II-1, II-4, and IV-3) were $\mathrm{C} / \mathrm{T}$ heterozygous (middle panel). Individual III-1 was not analyzed but is an obligate carrier

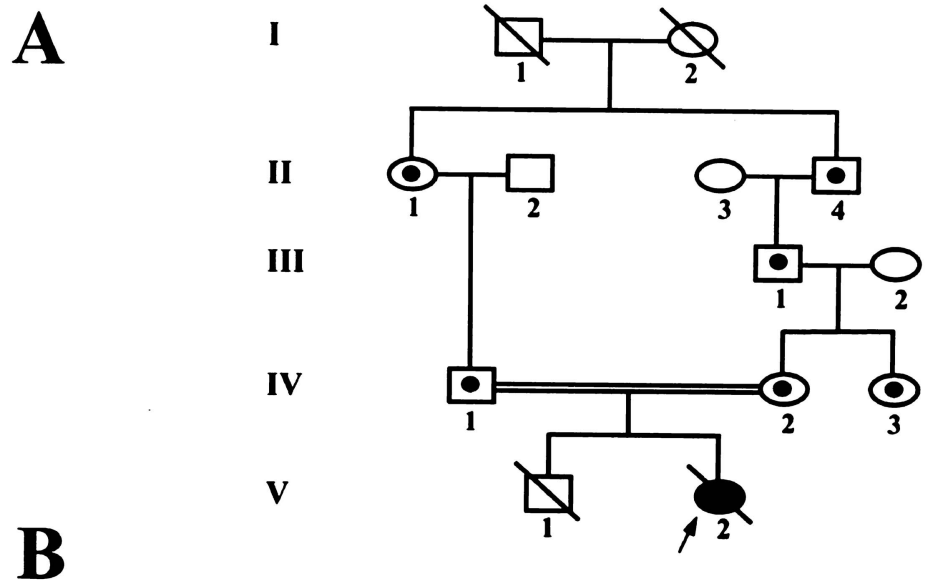

Normal

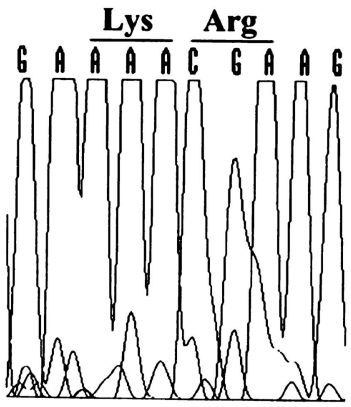

Heterozygous

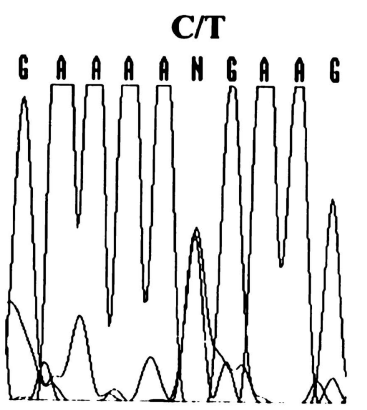

Mutant

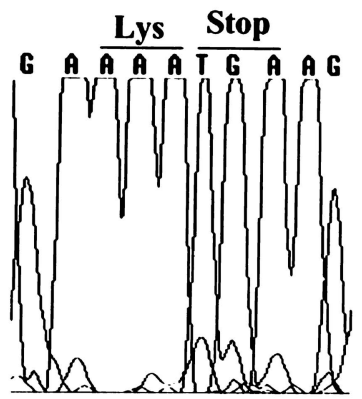

In this study, we report a homozygous new mutation in a sibling from a consanguineous Mexican family. The mutation, located on exon 54, corresponds to a substitution (C7781T) that produces a stop codon (Arg2578Stop) and therefore absence of the protein, which may eliminate one half of the globular domain, avoiding the linkage between merosin and the dystrophin-glycoprotein complex. Absence of the protein induces a severe CMD phenotype.

\section{Patient and methods}

Patient

The patient was admitted to the Hospital de Pediatria, Centro Medico Nacional Siglo XXI-IMSS when she was 8 months of age. This Mexican infant was the second child of healthy consanguineous parents (Fig. 1A). From the first month of life, the patient was hypotonic with poor intake, irritability, reduced spontaneous movements, and poor suction. Physical examination showed markedly generalized muscle weakness in limb-girdle muscles; contractures of elbows, wrists, knees, and ankles; and bilateral talipes equinovarus. Upper and lower extremities were hypertrophic. Serum CK concentration was $2897 \mathrm{U} / 1$ and lactate dehydrogenase was $454 \mathrm{U} / \mathrm{l}$. An MRI scan of the cerebral hemispheres and brainstem with a low signal intensity in T1-

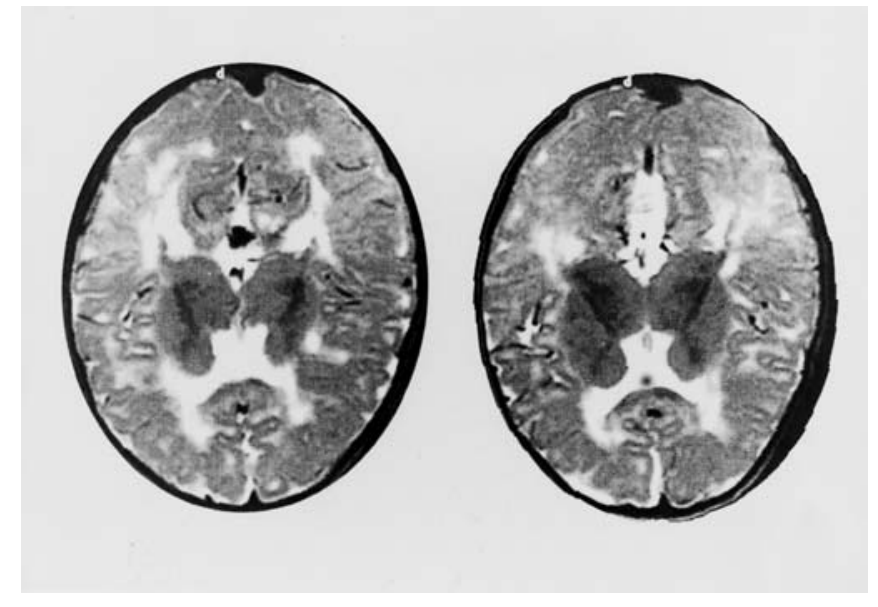

Fig. 2. Cerebral magnetic resonance imaging scan (T2-weighted image) of the patient. The transversal images show patchy areas of T2 hyperintensity of white matter

weighted images and a high signal intensity in T2-weighted images showed a myelinization pattern that corresponded to the age of 3 months (Fig. 2). There were areas of periventricular hyperintensity that corresponded to areas of demyelinization. A muscle biopsy specimen depicted diffuse atrophy of fibers with scarce, small rounded muscle fibers that alternated with several hypertrophic muscle fibers. 
Fig. 3. Immunocytochemical analysis of normal and patient muscle. Skeletal muscle cryosections were stained with monoclonal antibodies against $\alpha-, \beta-, \gamma-$, and $\delta$-sarcoglycan $(S G)$, dystrophin C-terminus $(D Y S)$, and laminin $\alpha 2$ as described in "Patient and Methods". Laminin $\alpha 2$ protein was absent on the surface of the patient's skeletal muscle fibers
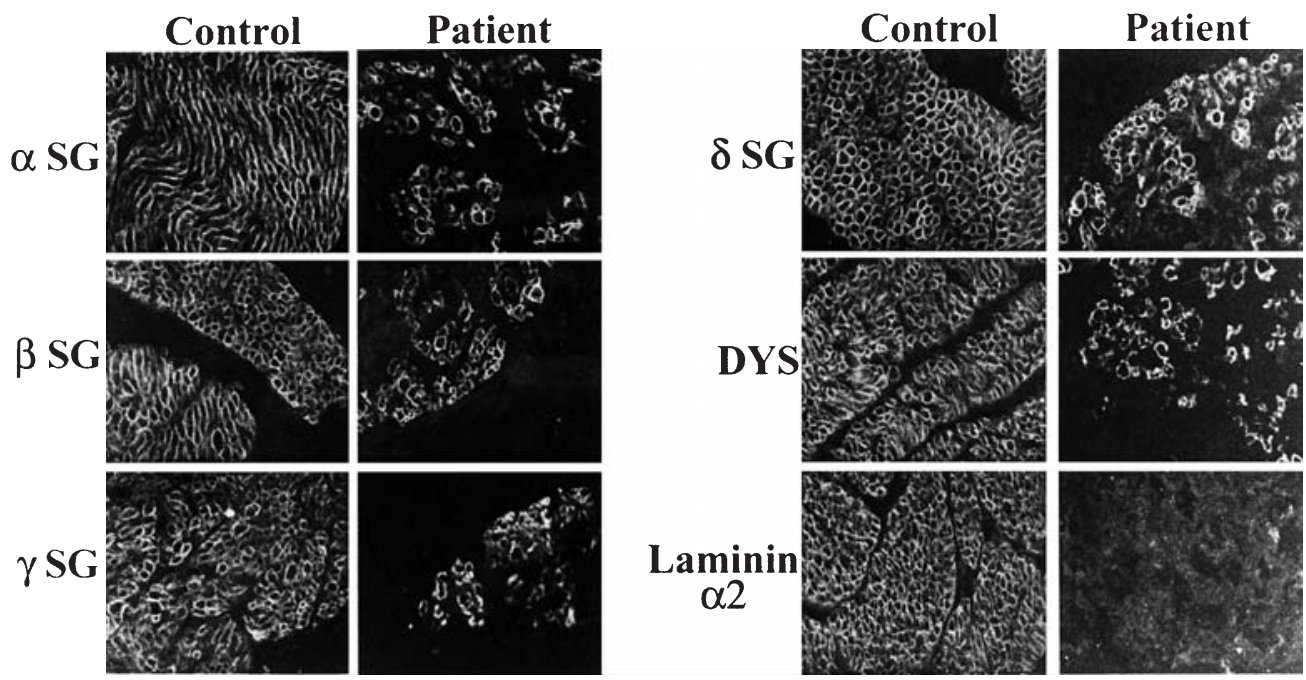

Immunofluorescence analysis

Skeletal muscle biopsies from patient and control quadriceps were frozen rapidly in liquid nitrogen-isopentane. Seven-micrometer muscle cryosections were blocked with $5 \%$ bovine serum albumin in phosphate-buffered solution (PBS) for $1 \mathrm{~h}$, and were then incubated with distinct primary antibodies for $3 \mathrm{~h}$. After several washes with PBS, sections were incubated with Cy3-secondary antibody (goat antimouse, Jackson ImmunoResearch, WestGrove, PA, USA) $(1: 250)$ for $1 \mathrm{~h}$. After rinsing with PBS, sections were mounted on Vectashield (Vector, Burlingame, CA, USA) and observed under an Olympus BX60 fluorescence microscope.

\section{Antibodies}

Mouse monoclonal antibodies were used against $\alpha$ sarcoglycan $(1: 200)$ (NCL-a-SARC, Novocastra, Benton Lane, Newcastle, UK), $\beta$-sarcoglycan $(1: 200)$ (NCL-bSARC, Novocastra), $\gamma$-sarcoglycan $(1: 200)$ (NCL-g-SARC, Novocastra), $\delta$-sarcoglycan (1:200) (NCL-d-SARC, Novocastra), dystrophin N-terminus $(1: 200)$ (NCL-DYS3, Novocastra), dystrophin C-terminus (1:200) (NCL-DYS2, Novocastra), and laminin $\alpha 2$ chain $(1: 1000)$ (NCLMEROSIN, Novocastra).

Molecular analysis of LAMA2

Genomic DNA was extracted from peripheral blood lymphocytes as described by Kempter (1992). Polymerase chain reaction (PCR) amplification of LAMA2 64 exons was carried out using primers and PCR touchdown conditions designed by Guicheney et al. (1998). Each amplification was performed using $100 \mathrm{ng}$ of genomic DNA in a $25-\mu \mathrm{l}$ reaction. PCR products were analyzed on $2 \%$ agarose electrophoresis gel and purified by Rapid Gel Extraction System (Marligen Bioscience, Ijamsville, MD, USA). Purified products were sequenced using a Big Dye kit (Applied
Biosystems, Foster City, CA, USA), an Applied Biosystems Automated Sequencer 3700, and the same primers as for PCR amplification.

\section{Results}

The patient was born into a consanguineous family in a small Mexican town and all clinical characteristics pointed to a diagnosis of classical CMD. Furthermore, hematoxilin: eosin staining of muscle sections of the child showed histopatology compatible with dystrophic changes characterized by fibrotic tissue, increase of fatic connective tissue, and few small surviving fibers (data not shown). To explore the possibility of merosin-deficient CMD (Tome et al. 1994), we analyzed cryosections of muscle biopsy by immunofluorescence using monoclonal antibody (see "Patient and Methods") directed against laminin $\alpha 2$. Immunostaining demonstrated a total absence of protein on the surface of the patient's muscle fibers (Fig. 3). In contrast, although there were very few small muscle fibers, it was possible to observed expression of all sarcoglycans $(\alpha-, \beta-, \gamma-$, and $\delta-)$ and dystrophin (Fig. 3).

All clinical features and protein expression results on the patient's muscle prompted us to analyze the laminin $\alpha 2$ gene. Each 64 exons of the gene were amplified by touchdown PCR (Guicheney et al. 1998) and a sequence of DNA products was obtained by automated sequencing. The nucleotide sequence of exon 54 in the patient's DNA revealed the presence of homozygous new point mutations at nucleotide position 7781 (Fig. 1B). The mutation was a $\mathrm{C} \rightarrow$ $\mathrm{T}$ transition that caused replacement of an arginine residue with a stop codon at amino acid position 2578 (R2578X).

To determine the presence of the mutation in other family members, we obtained an exon 54 nucleotide sequence of individuals II-1, II-4, IV-1, IV-2, and IV-3 (Fig. 1A,B). The patient's parents, obligate carriers, were heterozygous for the nonsense mutation, in addition to individuals II-1, II-4, and IV-1. Nevertheless, it was not possible to study 
other family members; thus, the carrier state of individual III-1 was inferred by the segregation pattern of the mutation.

\section{Discussion}

The first studies on laminin $\alpha 2$ deficiency CMD reported patients with a similar phenotype (Tome et al. 1994; Helbling-Leclerc et al. 1995; Dubowitz 1996) characterized by the presence of muscle weakness and hypotonia, a severe clinical course with inability to achieve independent ambulation, and abnormal white matter signal by MRI (Tome et al. 1994). In recent years, there have been several reports showing variability in the clinical phenotype associated with laminin $\alpha 2$ deficiency. In these cases, patients less severely affected presented a clinical course characterized by late-onset muscle weakness, achievement of ambulation, and a CK level below $1000 \mathrm{U} / \mathrm{l}$, with and without neuronal migration defects in MRI (Herrmann et al. 1996; Mora et al. 1996; Allamand et al. 1997; Naom et al. 1997; Morandi et al. 1999). Severe phenotypes can be induced by mutations that completely avoid expression of the protein (HelblingLeclerc et al. 1995; Nissinen et al. 1996; Pegoraro et al. 1996; Guicheney et al. 1998; Pegoraro et al. 1998); milder CMD phenotypes have been observed in patients with mutations that induce production of a reduced amount of normal protein or expression of a partially functional protein (Allamand et al. 1997; Naom et al. 2000).

Herein we describe a Mexican child from a consanguineous family with a classical CMD phenotype. The patient, who was studied at the age of 8 months and died at 12 months of age, never walked and had cerebral white matter changes in MRI, as reported in persons with complete absence of laminin $\alpha 2$ (Tome et al. 1994; Voit 1997). Results obtained by immunofluorescence with an antibody that recognized laminin $\alpha 2$ confirmed the absence of protein on the muscle fiber surface. In contrast, $\alpha-, \beta-, \gamma-$, and $\delta$ sarcoglycans and dystrophin were present on the muscle membrane. By immunofluorescence assay, it was not possible to determine whether there was alteration in expression of these proteins. However, Jones et al. (1998) reported a case with the absence of laminin $\alpha 2$ and abnormal staining with dystrophin and $\alpha$-sarcoglycan.

Pegoraro et al. (1998) observed, in a study of patients with complete deficiency of laminin $\alpha 2$, that the majority presented primary mutations on LAMA2. However, it has not always been determined that complete absence of laminin $\alpha 2$ is due to primary mutations on LAMA2 (Pegoraro et al. 1998; Guicheney et al. 1998). Recently, Jones et al. (2001) showed in a case series and review study that mutations confirming the primary abnormality of laminin $\alpha 2$ have been reported in only $25 \%$ of cases.

The patient described in our study had a homozygous mutation that corresponded to a $\mathrm{C} \rightarrow \mathrm{T}$ substitution, producing a stop codon (R2578X). It is located at the carboxyl terminus of the laminin $\alpha 2$ gene and predicts the loss of the last 532 amino acids, which may avoid linkage of merosin to $\alpha$-dystroglycan (Yamada et al. 1994). Disruption in the link between the extracellular matrix and the cytoskeleton can lead to basal membrane instability and muscle fiber necrosis (Xu et al. 1994; Campbell 1995; Minetti et al. 1996; Osari et al. 1996). Patients with a similar phenotype and mutations in other codons of the $\mathrm{G}$ domain of laminin $\alpha 2$ have been reported (Pegoraro et al. 1998; Allamand and Guicheney 2002). Mutation analysis carried out in parents and other relatives showed that one paternal grandmother, one maternal great-grandfather, and the patient's mother' sister (her maternal aunt) were carriers of the mutation. These results suggest that the mutation originated at least three generations ago and has been segregating in a broadly endogamic community.

In summary, we demonstrated that primary deficiency of laminin $\alpha 2$, caused by a new nonsense mutation that is segregating in an endogamic community, produced a phenotype of classical CMD. This information is important for correlating the molecular basis of muscular dystrophy with a clinical phenotype and for improving the quality of genetic counseling.

Acknowledgments The authors wish to thank Dr. Pascale Guicheney (INSERMU523, Institute de Myologie), who kindly provided us with the primers' sequences and PCR conditions to amplify exons of LAMA2. This work was supported by CONACYT (Mexico) grant 34603-M, and Fondo de Fomento para la Investigacion-IMSS (Mexico) grant FP-0038/764. All DNA sequencing was carried out at the Centro de Instrumentos del Instituto Mexicano del Seguro Social (IMSS), Mexico City.

\section{References}

Allamand V, Guicheney P (2002) Merosin-deficient congenital muscular dystrophy, autosomal recessive (MDC1A, MIM\#156225, $L A M A 2$ gene coding for alpha2 chain of laminin). Eur J Hum Genet 10:91-94

Allamand V, Sunada Y, Salih MA, Straub V, Ozo CO, Al-Turaiki MH, Akbar M, Kolo T, Colognato H, Zhang X, Sorokin LM, Yurchenco PD, Tryggvason K, Campbell KP (1997) Mild congenital muscular dystrophy in two patients with an internally deleted laminin alpha2chain. Hum Mol Genet 6:747-752

Banker BQ (1994) The congenital muscular dystrophy. In: Engel AG, Francini-Armstrong C (eds) Miology, vol 2. McGraw-Hill, New York, pp 1275-1289

Campbell KP (1995) Three muscular dystrophies: loss of cytoskeletonextracellular matrix linkage. Cell 80:675-679

Dubowitz V (1994) Congenital muscular dystrophy. In: Emery ARD (ed) Diagnostic criteria for neuromuscular disorders. Baarn, The Netherlands, pp 32-34

Dubowitz V (1996) New developments in congenital muscular dystrophy. Neuromuscul Disord 6:228

Guicheney P, Vignier N, Zhang X, He Y, Cruaud C, Frey V, HelblingLeclerc A, Richard P, Estournet B, Merlini L, Topaloglu H, Mora M, Harpey JP, Haenggeli CA, Barois A, Hainque B, Schwartz K, Tome FM, Fardeau M, Tryggvason K (1998) PCR based mutation screening of the laminin alpha2 chain gene (LAMA2): application to prenatal diagnosis and search for founder effects in congenital muscular dystrophy. J Med Genet 35:211-217

Helbling-Leclerc A, Zhang X, Topaloglu H, Cruaud C, Tesson F, Weissenbach J, Tome FM, Schwartz K, Fardeau M, Tryggvason K, Guicheney P (1995) Mutations in the laminin alpha 2-chain gene (LAMA2) cause merosin-deficient congenital muscular dystrophy. Nat Genet 11:216-218

Herrmann R, Straub V, Meyer K, Kahn T, Wagner M, Volt T (1996) Congenital muscular dystrophy with laminin alpha 2 chain defi- 
ciency: identification of a new intermediate phenotype and correlation of clinical findings to muscle immunohistochemistry. Eur J Pediatr 155:968-976

Hillarie D, Leclerc A, Faure S, Topaloglu H, Chiannilkulchai N, Guicheney P, Grinas L, Legos P, Philpot J, Evangelista T (1994) Localization of merosin-negative congenital muscular dystrophy to chromosome $6 \mathrm{q} 2$ by homozygosity mapping. Hum Mol Genet 3:1657-1661

Jones KJ, Kim SS, North KN (1998) Abnormalities of dystrophin, the sarcoglycans, and laminin alpha2 in the muscular dystrophies. J Med Genet 35:379-386

Jones KJ, Morgan G, Johnston H, Tobias V, Ouvrier RA, Wilkinson I, North KN (2001) The expanding phenotype of laminin alpha2 chain (merosin) abnormalities: case series and review. J Med Genet 38:649-657

Kempter B (1992) Quick preparation of high molecular weight DNA by freezing. Trends Genet 8:7

Minetti C, Bado M, Morreale G, Pedemonte M, Cordone G (1996) Disruption of muscle basal lamina in congenital muscular dystrophy with merosin deficiency. Neurology 46:1354-1358

Mora M, Moroni I, Uziel G, Di Blasi C, Barresi R, Farina L, Morandi L (1996) Mild clinical phenotype in a 12-year-old boy with partial merosin deficiency and central and peripheral nervous system abnormalities. Neuromuscul Disord 6:377-381

Morandi L, Di Blasi C, Farina L, Sorokin L, Uziel G, Azan G, Pini A, Toscano A, Lanfossi M, Galbiati S, Cornelio F, Mora M (1999) Clinical correlations in 16 patients with total or partial laminin alpha2 deficiency characterized using antibodies against 2 fragments of the protein. Arch Neurol 56:209-215

Naom IS, D'Alessandro M, Topaloglu H, Sewry C, Ferlini A, HelblingLeclerc A, Guicheney P, Weissenbach J, Schwartz K, Bushby K, Philpot J, Dubowitz V, Muntoni F (1997) Refinement of the laminin alpha2 chain locus to human chromosome $6 \mathrm{q} 2$ in severe and mild merosin deficient congenital muscular dystrophy. J Med Genet 34:99-104

Naom I, D'Alessandro M, Sewry CA, Jardine P, Ferlini A, Moss T, Dubowitz V, Muntoni F (2000) Mutations in the laminin alpha2chain gene in two children with early-onset muscular dystrophy. Brain 123:31-41
Nissinen M, Helbling-Leclerc A, Zhang X, Evangelista T, Topaloglu H, Cruaud C, Weissenbach J, Fardeau M, Tome FM, Schwartz K, Tryggvason K, Guicheney P (1996) Substitution of a conserved cysteine-996 in a cysteine-rich motif of the laminin alpha2-chain in congenital muscular dystrophy with partial deficiency of the protein. Am J Hum Genet 58:1177-1184

Osari S, Kobayashi O, Yamashita Y, Matsuishi T, Goto M, Tanabe Y, Migita T, Nonaka I (1996) Basement membrane abnormality in merosin-negative congenital muscular dystrophy. Acta Neuropathol (Berl) 91:332-336

Pegoraro E, Mancias P, Swerdlow SH, Raikow RB, Garcia C, Marks H, Crawford T, Carver V, Di Cianno B, Hoffman EP (1996) Congenital muscular dystrophy with primary laminin alpha2 (merosin) deficiency presenting as inflammatory myopathy. Ann Neurol 40:782-791

Pegoraro E, Marks H, Garcia CA, Crawford T, Mancias P, Connolly AM, Fanin M, Martinello F, Trevisan CP, Angelini C, Stella A, Scavina M, Munk RL, Servidei S, Bonnemann CC, Bertorini T, Acsadi G, Thompson CE, Gagnon D, Hoganson G, Carver V, Zimmerman RA, Hoffman EP (1998) Laminin alpha2 muscular dystrophy: genotype/phenotype studies of 22 patients. Neurology 51:101-110

Sewry CA, Philpot J, Mahony D, Wilson LA, Muntoni F, Dubowitz V (1995) Expression of laminin subunits in congenital muscular dystrophy. Neuromuscul Disord 5:307-316

Tome FM, Evangelista T, Leclerc A, Sunada Y, Manole E, Estournet B, Barois A, Campbell KP, Fardeau M (1994) Congenital muscular dystrophy with merosin deficiency. C R Acad Sci III 317:351-357

Voit T (1997) Congenital muscular dystrophies: update. Brain Dev 20:65-74

Xu H, Christmas P, Wu XR, Wewer UM, Engvall E (1994) Defective muscle basement membrane and lack of M-laminin in the dystrophic dy/dy mouse. Proc Natl Acad Sci USA 91:5572-5576

Yamada H, Shimizu T, Tanaka T, Campbell KP, Matsumura K (1994) Dystroglycan is a binding protein of laminin and merosin in peripheral nerve. FEBS Lett 352:49-53

Zhang X, Vuolteenaho R, Tryggvason K (1996) Structure of the human laminin alpha2-chain gene (LAMA2), which is affected in congenital muscular dystrophy. J Biol Chem 271:27664-27669 